\title{
Social Network and Inter-Organizational Learning: The Case of a Brazilian Cooperative of Fish-Farmers
}

\author{
Andreia Maria Kremer ${ }^{1}$, Edson Talamini ${ }^{2}$ \\ ${ }^{1}$ Federal University of Grande Dourados, Dourados, Brazil \\ ${ }^{2}$ Department of Economics, Federal University of Rio Grande do Sul, Porto Alegre, Brazil \\ Email: andreiakremer@ufgd.edu.br
}

Received February 27, 2013; revised March 28, 2013; accepted April 20, 2013

Copyright (C) 2013 Andreia Maria Kremer, Edson Talamini. This is an open access article distributed under the Creative Commons Attribution LiceNES, which permits unrestricted use, distribution, and reproduction in any medium, provided the original work is properly cited.

\begin{abstract}
The inter-organizational learning approach has shown considerable growth in recent years. The concepts of trust and cooperation between individuals present in the New Economic Sociology (NES) approach of social relations emerge with great emphasis and are gaining prominence as a facilitator and propellant mechanism in transferring knowledge inside networks. This study aims to analyze the learning networks formed by fish-farmers organized into a cooperative to identify the characteristics of the network through structural analysis and identification of its critical actors. The study was performed with thirteen fish-farmers of a cooperative headquartered in Mundo Novo county, which is located in Mato Grosso do Sul state in the Midwest region of Brazil. Questionnaires and interviews with closed and open questions were used to collect the data. Measures of centrality (for individuals), density and reciprocity (in relations between individuals) were obtained from ORA software. The findings revealed that experience exchanges between fish-farmers, events participation, meetings attendance, speech audience and technical advice are the main forms of inter-organizational learning. Results suggest that the network has low levels of cohesion and that it is not taking advantage of its full potential. It was also found that there is a subgroup within the network that presents a high level of cohesion and shared learning based on cooperative informal relationships. Grounded in findings, suggestions for future research are presented.
\end{abstract}

Keywords: New Economic Sociology; Cooperation; Trust; Social Relations

\section{Introduction}

Organizational structures have shown changes over the years, as evidenced mainly by analytical structures of supply chains. These changes have resulted in major impacts on competitive strategies, thus forcing organizations to establish organizational arrangements based on cooperation with other organizations.

The search for external partners to leverage the development and growth of an organization is required because it has limited human, financial and technical resources. To overcome these constraints, organizations can develop interactivity with their environment. Modern organizations are able to capture external resources through cooperation and develop cooperation networks with new partners [1]. In a competitive environment, cooperation networks become instruments of exchange of information and technology, transaction cost reduction and increase in market access.
According to this rationality, new inter-organizational arrangements, such as networks of firms, can be considered a propellant factor of organizational learning in the network, providing access and sharing knowledge with other partner companies. In this line of thought, developing more inter-organizational arrangements is one of the advantages that an integrative network provides to organizations, specifically to the small ones.

According to [2], learning through social networks is strengthened by the argument that small business owners learn through networks based on a list of conditions that include the following: limited internal resources, dependence on external factors, economic and social involvement in the community, the need to reduce uncertainty within the environment and cooperative behavior with other network members.

Faced with the possibility of learning through inter-organizational networks widely disseminated in various sectors among agribusiness, it is necessary to analyze 
how learning takes place in cooperative inter-organizational networks. Considering that inter-organizational learning will only be effective if there is collective sharing, the New Economic Sociology (NES) was adopted as theoretical support. The NES approach states that transactions must be based on social relations fitted with mutual trust among agents. As an analytical and empirical case, we chose to analyze a small-scale cooperative of fish-farmers that is located in the county of Mundo Novo in the Mato Grosso do Sul state, Brazil. In everyday life, the cooperation and networking provide competitive advantages that enable the fish-farmers to access the market for their products.

This study aims 1) to identify the characteristics of the social network formed by fish-farmers through the structural analysis of networks and critical actors to promote knowledge sharing throughout the network, and 2) to explore the role of the social relations network in obtaining inter-organizational learning.

To that end, the paper is organized to present a discussion about cooperation networks from the conceptual evolution of the concept of agribusiness. Further, it presents a review of NES, discussing the role of trust and social relations in organizational learning. Following the methods section, the results are presented and discussed. Finally, considerations about the influence of social relationships on the learning process are summarized. In the concluding remarks, limitations of the study are presented and suggestions for future research are provided.

\section{Cooperation Networks}

Studies of business organizations and their ways of achieving competitive advantages through cooperation between companies evolve constantly. Reference [3] argued that in agribusiness it was no longer possible to analyze the economy in a traditional way with isolated sectors that manufactured inputs, processed products and marketed them. They were the precursors of the systemic view of agribusiness, which extends from the farmers' supplier to the end consumer.

The conceptual evolution of agribusiness has utilized a few theoretical schools of analytic frameworks over time, evolving to the Social Netchain concept [4], which is motivated by the need for companies to act jointly and in association. The concept of networks presents a theoretical orientation that prioritizes business development through association, sharing, exchange and mutual aid. Consistent with the network features, Fensterseifer [1] defines the network as an arrangement of "complex cooperative relationships that streamline the action of its agents around common or complementary goals”.

For the social sciences, networks usually refer to movements that gather small institutionalized groups or individuals in associations that have variable terms. In this context, networks are “(...) composed of individuals, groups or organizations, and their dynamic is facing the perpetuation, consolidation and development of the activities of its members" [5]. According to the author, networks are informal bodies formed by a set of autonomous individuals that unite resources and ideas toward common interests.

According to [6], "Social networks are multi-shaped structures formed necessarily by social actors linked by formal or informal ties.” For the most part, the concepts of a network consider the need for individuals to associate with others with common goals as a propellant of networking and therefore make use of social relations as a mechanism for choice of network components and maintenance of common goals. The conceptual characteristics of networks entail different approaches in the Sociology field, particularly with the beginning of studies of social relations by NES.

\section{New Economic Sociology and Social Relations}

The approach of social relations in theoretical NES began in the 1970s, with the doctoral thesis of Mark Granovetter, titled “Getting a Job” [7], which focused on the study of the dynamics of markets observed as extrapolations of social networks. According to the point of view of Granovetter, NES would have as its main focus the argument that economic activities are rooted in personal networks and that these personal networks also create networks of enterprises [8]. The social actor is shaped by a set of social relations that he/she establishes with other authors, and that all other actions, phenomena and economic institutions are only meaningful if they are considered in their inclusion in significant social relations networks [9].

Conceptualizing the NES, [9] states that NES “(...) deals with the study of the social mechanisms that provide a continued social relations network, noting the ways in which these relationships are the foundation for building contracts, firms, organizations, business groups and economic institutions”. Adopting the concept of embeddedness proposed by Granovetter, social relations embedded in networks possess three characteristics that control the expectations and behavior of agents in relationships: trust, information exchange and joint problem solving [10].

According to [11], "networks are formed without any formal contract that establishes rules; they act in accordance with the interests of mutual cooperation, based mainly on trust between the actors." The social relations among actors, organizations and institutions develop from a network of references or previous relationships and form a network of trust relationships [10]. The exchange of information over time strengthens the ties of 
exchange and joint problem solving; therefore, organizational relationships can positively affect organizational and economic outcomes through trust in exchanges.

The approach of trust in exchange relationships is presented by [12] in their study of trust as a competitive advantage, which asserts that behavioral scholars and economic experts have different definitions of trust in exchange relationships. On the one hand, economic scholars who have a more rational approach state that the trust in exchange relationships only emerge before formal governance mechanisms such as contracts and standards because of the difficulty in identifying agents that are reliable. On the other hand, scholars argue that the behavioral economic approach is incorrect and inefficient because all agents are trustworthy and costs with formal governance mechanisms are unnecessary.

Reference [13] presents the approach of trust in exchange relationships by focusing on the definition of inter-organizational trust. The author asserts that trust is a social phenomenon that favors labor among organizations, therefore making it easier and more collaborative. Trust provides a way of dealing with risk and uncertainty in exchange relationships.

In addition to the advantages in the reduction of risks and uncertainties in transactions, trust can still serve as a tool of social control by influencing the magnitude of knowledge exchanged and the efficiency in which knowledge is shared in cooperative relationships [14]. Given the efficiency of the exchange of knowledge in social networking situations in which individuals trust one another, trust emerges as a driver of organizational learning among network participants.

\section{Organizational Learning and Cooperation Networks}

The term "learning", by its cognitive and multidisciplinary nature, has no single definition adopted and assumes different definitions in different areas of knowledge independent of individual or organizational approach. According to [15], despite the growing use of the term organizational learning, there is little coNESnsus about definitions, applications, methodologies and contextualization.

The concept of organizational learning adopted by [16] is that it is a dynamic process because learning occurs at all times and at all levels of the organization and also creates a type of tension related to the assimilation of new knowledge. Moreover, the routines of learning are characterized as a regular pattern of interactions between individuals that allows the transfer, recombination or creation of specialized knowledge [17].

Reference [18] defines organizational learning as a set of internal processes that provide the maintenance or improvement of performance based on experience, and this performance improvement involves the acquisition, sharing and use of knowledge. Given the concept presented by the author, it appears that network integration emerges as the driver of organizational learning because the openness and richness of networks enable the creation of a fertile environment for the production of new knowledge and its sharing. The organization cannot create knowledge by itself; it requires the interaction between the individual and the individuals within the organization [19].

Reference [17] argues that the learning ability of a company goes beyond its capacity as a single and isolated entity and requires the analysis of the network in which the company operates. The company should be able to create and position themselves in these learning networks by building routines for knowledge sharing among participating members. Based on the concepts presented by $[17,19]$ that learning occurs in a collective way with the interaction between individuals, the concept of inter-organizational learning is proposed, which, according to [20] "(...) can then be seen as a collective acquisition of knowledge among a set of organizations”.

Reference [20] argues that inter-organizational learning occurs through the transfer of existing knowledge from one organization to another, as well as through the creation of new knowledge through interaction between organizations. However, for the process of inter-organ izational learning to be effective and suffer no opportunistic interference from any of those involved, it must be founded on trust, transparency and cooperation. Following this logic, according to [20], the creation and transfer of knowledge require levels of transparency and openness between organizations that establish partnership relations.

In addition to the points raised by [20], some variables may also influence the shape and intensity of inter-organizational learning. Reference [21] asserts that cultural, structural, technological and absorptive structural factors should be considered. Culture influences the process of learning to relate to change because organizations with greater flexibility for change have greater success in the learning process. The technology, in turn, facilitates the learning process through knowledge transfer and more practical connection with other organizations.

Regarding the network structure, the focus of this study, [21] states that this variable can be evaluated by the following items: number of organizations in the network; the location of a participating organization in a network; the levels of connections among participating organizations; the embeddedness of the structure in other networks; and the presence or absence of boundary-spanning roles. These factors are important in the analysis of the learning process, as they can influence the process of 
creation and knowledge transfer. In networks with fewer organizations, there is less ability to create and identify new ideas. Moreover, the proximity between the agents makes it easier to share information. In addition, actors with higher levels of centrality in a network can achieve higher levels of learning because of their broader access to information and the enjoyment of the highest levels of trust with other agents [21].

\section{Methods}

Aiming to analyze inter-organizational learning networks, we chose to analyze the network of fish-farmers in a cooperative named COOPISC, headquartered in the county of Mundo Novo in Mato Grosso do Sul state, the Midwest region of Brazil. After defining the case to be studied, we performed an analysis of the structure of COOPISC with the goal of identifying the fish-farmers to be addressed in the study. The fish-farmers' cooperative has 21 members. Interviews were conducted, and a questionnaire was utilized for 13 fish-farmers (62\% of total cooperative members) because of the unavailability of other fish-farmers to participate in the study. Data collection was performed in one day, and those who were not available could not be interviewed. The interview and the questionnaire aimed to identify individuals, their relationships and forms of learning in the network, and based on the collected data, to analyze the level of cooperation and cohesion in the group. Simultaneously, documentary research was conducted to identify the history and features of COOPISC.

Following completion of the data collection phase, the data were analyzed with the aid of software for social network analysis, ORA v.2.3.6, calculating measures of centrality and prestige and identifying the position of each fish-farmer in the network. Finally, we created the relations matrix and obtained the network design by using the resources of the ORA software. Thus, it was possible to visualize and measure several indexes, such as density, centrality and betweenness centrality, for each fish-farmer, a group or the network as a whole.

Reference [22] uses Equation (1) for calculating the density $(D)$ of a network:

$$
D=\frac{2 \times L_{t}}{N \times(N-1)}
$$

in which $N$ is the number of nodes in the network, where $N>1$, and $L_{t}$ is the total number of links between the nodes.

In addition to the density, we analyzed the centrality of agents and identified the degree of centrality of fishfarmers in the network. The main indexes of centrality are closeness centrality, betweenness centrality and degree centrality.

Reference [22] presents Equation (2) to calculate the closeness centrality $(C c)$ :

$$
C c(p k)^{-1}=\sum_{i=1}^{n} d\left(p_{i}, p_{k}\right)
$$

in which $d\left(p_{i}, p_{k}\right)$ is the number of shorter rows linking the actors $i$ and $k$ and $\sum_{i=1}^{n}$ is the sum of the total distance of $i$ to all other actors.

The betweenness centrality $(C b)$ of a network as a whole may be obtained by Equation (3), according to [22]:

$$
C b\left(V_{k}\right)=\sum_{i}^{n} \sum_{j>i}^{n} b_{i j}\left(V_{k}\right)
$$

in which $\sum_{i}^{n}$ is the sum of all different pairs of nodes $v_{i}$ and $v_{j}$ and $b_{i j}\left(V_{k}\right)$ is the betweenness centrality value between actors $i$ and $j$.

For calculating the degree centrality ( $\mathrm{Ci}$ ) between two nodes, [22] utilizes Equation (4):

$$
C i=\sum_{j=1}^{n} L_{i j} /(N-1)
$$

in which $N$ is the number of nodes in the network. In this equation, $L_{i j}=1$ if there is a link between the nodes $i$ and $j$ and $L_{i j}=0$ if there is not a link between both nodes.

To guarantee and respect the individuality and anonymity of fish-farmers, their real names will not be mentioned in this paper. Thus, the personal names presented in this study are merely illustrative and therefore do not correspond to the individuals interviewed.

\section{Results and Discussions}

\subsection{The History of COOPISC and Fish-Farmers' Profile}

The study was conducted in the municipality of Novo Mundo, which is located in the south region of Mato Grosso do Sul state, Brazil. Mundo Novo has approximately 17,000 inhabitants, according to [23], and is bordered by Guaira city, Paraná state, and the Paraguayan city of Salto Del Guayrá. Mundo Novo has as its main feature the clay soil and the richness of the waters irrigating the region that provides favorable conditions for the development of fish farming activities. Mundo Novo has an organized group of fish-farmers who occupy a prominent position in the Mato Grosso do Sul state. That group is organized in a cooperative organization named COOPISC.

COOPISC was established in December 1999 with the main objective of marketing the fish produced by its members and purchasing supplies for fish farming. At its 
founding, COOPISC added 27 small producers and fish farmers, and over the years, there were some additions and outgoing members, leading to its current holding of 21 members. In 2000, COOPISC received a donation of land from the municipality for the construction of a warehouse for processing fish. In 2002, the cooperative had the financial resources to build the warehouse, which was partly funded by the Brazilian federal government and Banco do Povo (People's Bank) financing. However, with the commencement of warehouse operations, fishfarmers observed some deficiencies in the structure and equipment because the warehouse did not have enough capacity to process the entire supply of fish. The warehouse became operational in March 2008 and operated until April 2009, when it ended its activities to study restructuring.

As mentioned before, COOPISC currently has twentyone members, but because of unavailability to participate in interviews, only thirteen fish-farmers were interviewed. Twelve fish-farmers are male, and one is female; one fish-farmer falls in the 21 - 30-year-old age group, four in the 31 - 40-year-old age group and five in the 41 50 -year-old age group. Three fish-farmers are more than 50 years old. Therefore, there is a predominance of male fish-farmers with an older age. Regarding education, the group is divided into three levels of schooling. The first group is formed by seven fish-farmers who have less than eight years of formal schooling; the second consists of three fish-farmers who have completed eleven years of formal schooling; and the group of producers with more than eleven years of schooling totals three fish-farmers.

Only three fish-farmers have been living in the Mundo Novo region for less than 20 years. Living together for a long time can be a factor generating trust among fishfarmers because trust is based on past experience, and over time, strong ties of trust can be established. According to [24], "trust evolves as mutual cooperation initiates and knowledge on partners will be obtained."

Corroborating the idea proposed by [24], Child [25] states that a cooperative alliance develops over time in terms of a life cycle. According to the authors, as the participating actors interact and exchange experiences, they broaden the ability to work together and deepen cooperation. Another factor that is associated with the time of living is the time of belonging to COOPISC. For instance, COOPISC founders are the fish-farmers who have lived in the region for the longest time.

Asking fish-farmers about the advantages that COOPISC provided, the main advantages are as follows: increase in sales, more access to technical information, increase in the ties of friendship and exchange of experiences and participation in events and training. These advantages demonstrate that COOPISC influences factors that di- rectly affect inter-organizational learning.

\subsection{The Inter-Organizational Learning Network}

The results of this study confirm the proposition that organizational networks are enabling environments for creating and sharing knowledge. As described earlier, the COOPISC provided to its members greater access to technical information, talks and events beyond the degree that the cooperative provides an increase in the bonds of friendship and the exchange of experiences. The increase in friendships positively influences trust for the transmission of information that may be useful for the entire group and creates space for the exchange of experiences that are extremely important for the generation of new knowledge.

The importance of exchanging experiences can be viewed from the perspective of fish-farmers as it relates to learning. When asked to identify the main sources of learning relating to fish farming and property management that could indicate more than one alternative, twelve (92.3\%) fish-farmers stated that the main source of learning was to exchange experiences with other fishfarmers. This was the most frequently cited source of learning, followed by events participation, meetings attendance, and speech attendance with five citations and technical advice with four entries.

To identify the network of shared learning in COOPISC, respondents were questioned to indicate the name of members who exchange more information and generate higher learning among the group in order of importance. Respondents noted a minimum of four and a maximum of six indications.

Based on the respoNESs, we created a squared matrix in which rows generate relationships of origin and columns generate destination relations. Reference [26] states that "the matrices represent the relationships between individuals through the valuation of each relationship (...), where individuals are arranged in rows and columns and the value of the social relationship between two individuals compose the matrix elements.” The social matrix was built directly into a spreadsheet and then imported into the software for network analysis.

After the social matrix preparation, the indexes for analyzing the structures of social networks were calculated and the network of learning relationships of COOPISC was designed. Figure 1 illustrates the network of learning relationships formed by COOPISC members.

Following the theoretical assumption proposed by [21] about network structure, the focus of this study, the network will be analyzed according to the following variables: number of organizations in the network; the position of each participating organization in the network structure; and the level of ties between organizations and embeddedness of the network structure. The analysis is 
based on the effect of these variables on the generation and sharing of information and knowledge, that is, an analysis of how the network can provide transmission of knowledge through the individuals' relationships.

The COOPISC social network is a shortly extended network with few individuals involved. Our study considered only the producers' levels in supply chain producers. However, despite the limited number of actors, it is possible to analyze the network by metrics adopted by [21]. Table 1 presents the main metrics for COOPISC network.

According to [27], “The size of a network is the total effective ties (real relationships) in a particular group of individuals." The network of learning relationships of COOPISC is composed of fourteen individuals. One of them was not interviewed, but being cited by others as a source of learning, he/she was included in the network. The size is the most important structural feature of a network, whereas all other metrics have their structural computation based on the network size. The number of ties also reflects the profile of the network because from the total number of possible ties, only 56 are being carried out, with an average of four ties by each individual.

Density is another important metric for the characterization of a network. The density of a network is obtained by dividing the number of ties by the total number of possible ties. According to the definition proposed by [28], the density represents the ratio between the number of existing ties on a given network and the number of possible or potential ties, including those that are not necessarily being carried out. Sharing the identical concept, the density “(...) represents the current number of ties in a social network in relation to the use of total number of nodes. A social network with maximum density takes the value 1.0, which means that all nodes are connected with each other" [26].

Reference [29] associates the concept of density with the capability to exchange information. Thus, when the network is deNESr, the exchange of information is more inteNES, and vice versa. Based on the findings, the COOPISC network has a low density, with $30.8 \%$ of possible ties being carried out, which indicates that each fish-farmer individually has ties with a minority of the members in the network. The density of a network can also be a factor to identify the potential communication within the network. “(...) The density is an index of potential communication between parts of a network and thus is an index of the quantity and types of information that can be exchanged" [27].

The low density of the COOPISC network may be related to the fact that some fish-farmers have a greater amount of ties than others, as indicated in Figure 1. These fish-farmers are extremely important for the transmission of knowledge in the network. Withdrawing
Table 1. Metrics for COOPISC network.

\begin{tabular}{cc}
\hline Metric & Value \\
\hline Number of Individuals & 14 \\
Number of Ties & 56 \\
Density & 0.308 \\
Reciprocity & 0.302 \\
Clustering Coefficient & 0.551 \\
Betweenness Centrality & 0.138 \\
Closeness Centrality & 0.027 \\
\hline
\end{tabular}

Source: research data.

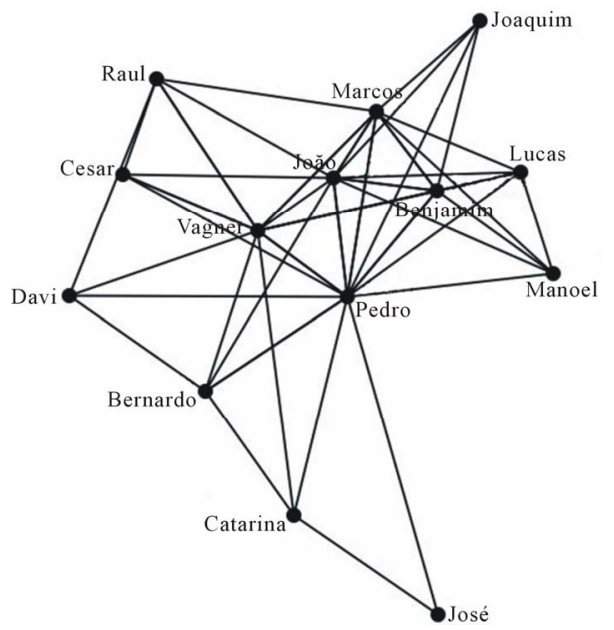

Figure 1. Network of learning relationships of COOPISC.

them from the flow of information, the learning in the network can be reduced by breaking the ties, at least temporarily, until new communication channels can be built. This demonstrates that, on one hand, the low density relations overload some individuals in the network; on the other hand, they make the knowledge transmission throughout the network dependent on such individuals.

The reciprocity indicates the degree of cohesion in a network in which all pair-to-pair relations are mutual, that is, whether there is a reciprocal transfer of learning between two members. A relationship is reciprocal when it flows in both directions, i.e., actor $A$ trusts actor $B$, and actor $B$ also trusts actor $A$ [29].

Reference [30], studying the role of social networks and reciprocity in local development, states that “(...) the reciprocity can consolidate social relations because it links the individuals through their behavior (i.e., moral obligations and reciprocal freedom to act) and the symbolism of giving and giving back.” Agreeing with this view, the inter-organizational networks seek common interests and goals. In the COOPISC network, the reciprocity index is $30.2 \%$; that is, the relationships are not reciprocal and therefore tend to be less effective.

The metric most often used in social network analysis 
is the centrality index of a network as a whole or of an individual who takes part in the network. Centrality is defined by [31] as "the extent to which a person is in the center of a network. Central people have more influence in their network, tend to receive better performance reviews, and tend to be more satisfied with their jobs than people who are less central”. An actor has a locally central position if he has many connections with other local points and will be globally central if he has a significant strategic position in the network as a whole [28].

The centrality identifies the most central actors in terms of overall network structure, in which the centrality of an actor is the sum of his/her ties with other actors. The centrality measures are divided into various approaches, and the most common are degree centrality, betweenness and closeness. In addition to these, the information centrality can still be considered, which can significantly influence knowledge transfer in the network [29-32].

The closeness centrality is defined by [33], stating that, "The closeness centrality can be calculated by raising the minimum number of connections that an actor must go through to get in touch with any other member of the network." According to the closeness centrality, an individual with the largest index is the person who requires the lowest number of nodes to reach all other individuals in the network [31]. This index demonstrates the independence of an actor in relation to the control of others. In a closeness centrality seNES, the individual is considered central, as he/she can avoid the potential control of others by focusing on the distance of an individual to all others in the network [34]. Thus, the independence of an individual is greater with a closer relationship with other individuals. When considering the network formed by all fish-farmers, it was observed that the closeness centrality index is 0.027 , indicating that most of the relationship has a significant distance, which may be a cause of delay in information transfer and hence a barrier to learning.

The betweenness centrality measures the degree to which an individual is positioned as a link between other individuals who are not directly connected [34]. According to [29], the betweenness centrality calculates the potential of links that serve as intermediaries or as a network bridge. These intermediate individuals are considered enablers in the flow of information between the network links.

The betweenness centrality of COOPISC's overall network is 0.138 . This value was boosted by the high degree of betweenness of six fish-farmers, as shown in the individualized analysis of network members in Table 2. The betweenness centrality of a node is calculated by the percentage of ties that go through a node (i.e., fishfarmer). Individuals or organizations that are potentially influential are positioned in intermediate ties and can use
Table 2. Highest betweenness centrality index among COOPISC members.

\begin{tabular}{ccc}
\hline & COOPISC member & Value \\
\hline 1 & Pedro & 17.308 \\
2 & João & 14.850 \\
3 & Vagner & 12.500 \\
4 & Lucas & 5.128 \\
5 & Benjamin & 4.915 \\
\hline
\end{tabular}

Source: research data.

the influence of a subgroup on the other.

According to the betweenness value presented in Table 2, Pedro is the fish-farmer who has the greatest power brokering. He has major ties that bind two or more individuals. In his absence, the relationships would be broken. Pedro's degree of betweenness centrality is 17.308, followed by João and Vagner with 14.850 and 12.500, respectively. According to [5], an individual may have weak relationships but a high power in the network because of his/her high power brokering information over the network.

The information centrality is another variable that can significantly influence the learning in the network. The information centrality is the measure that indicates which individuals have greater centrality in exchanging information, i.e., one that because of his/her central positioning receives information from most members of the network, therefore making it a strategic source. According to [29], this index assesses whether an actor is central to the access and exchange of information. Information centrality considers the strategic positioning of the individual even if he/she is not in a central position in the network in which his/her position provides connections with individuals widely distributed throughout the network. Information centrality is based on the concept of information using a combination that analyzes all ties between actors. For each analyzed tie, it considers the information contained in the corresponding tie [35].

This measure was created by [32] as an additional resource because other measures of centrality uses the shortest paths in their calculation. According to the authors, the flow of information can use any available channel in a network, and this is not always the shortest. Thus, they created the concept of information centrality. In this analysis, what is important is not who conveys information to whom, but whether there is a way in which information can flow. Table 3 shows the fishfarmers with the highest scores of information centrality.

In popular or cooperative organizations similar to COOPISC, it is important to identify individuals who possess information centrality because they may become important leaders and transmitters of knowledge in the network. Analyzing the index of information centrality, it 
Table 3. Highest information centrality index among COOPISC members.

\begin{tabular}{ccc}
\hline & COOPISC member & Value \\
\hline 1 & Lucas & 8.304 \\
2 & João & 7.949 \\
3 & Joaquim & 7.913 \\
4 & Davi & 7.913 \\
5 & Manoel & 7.896 \\
\hline
\end{tabular}

Source: research data.

appears that the fish-farmers have similar values; that is, all respondents have access to the information of the entire network.

After the analysis of the betweenness centrality by fish-farmers and the structure of the network represented by Figure 1, we will present and discuss the results on overall network centrality. The degree centrality is measured by the number of ties that an actor has with other actors in a network [22]. According to [36], when many ties are directed to an actor, we can say that he/she has prestige in the network; once many other actors seek to share information with him/her, this may indicate their importance. Such individuals are identified by relevant degree centrality in the social network once they have more ties with others in the identical network.

Reference [29] divides the degree centrality into input centrality and output centrality. The input centrality measures the number of ties that an actor receives from other actors, denoting openness and popularity. The output centrality measures the number of ties that an actor establishes with other actors in the network, which demonstrates expansiveness.

Table 4 shows the highest degree centrality values of fish-farmers, considering the relationships they have with other members in the network.

The results in Table 4 show that COOPISC has a group of fish-farmers who have more homogeneous relations than the other members. These members make up the core group in the generation and transmission of knowledge. The core group is represented by fish-farmers Vagner, Pedro, Marcos, Benjamin, João, Lucas and Bernardo. This group has a high concentration of power that may have been caused by the inteNES involvement of these members in decision-making and COOPISC activities as perceived during interviews.

When considering that a network may contain subgroups with a high level of trust between its members, we decided to analyze this subgroup of six fish-farmers and their relations by using the metrics for social network analysis. The subgroups consist of subsets formed by actors and their relationships. The subgroups analysis using specific criteria has been considered an important issue in social network analysis [22]. Reference [37] de- fines a subgroup as a subset of all the actors and relational ties between them. Figure 2 shows the selected subgroup of fish-farmers in the COOPISC learning network.

The results presented in Figure 2 suggest that subgroup members have closer and cohesive ties with almost every other member, as shown in Table 5.

The selected subgroup consists of six fish-farmers who generate 23 relations of learning exchange, generating an average of 3.8 ties per member, which is a high average compared to the COOPISC network as a whole. The high average of ties between members is reflected in the subgroup network density with an index of 0.767 . This indicates that the total number of possible ties between members, i.e., 76.7\%, is effective. By comparing the density of the COOPISC learning network in its totality

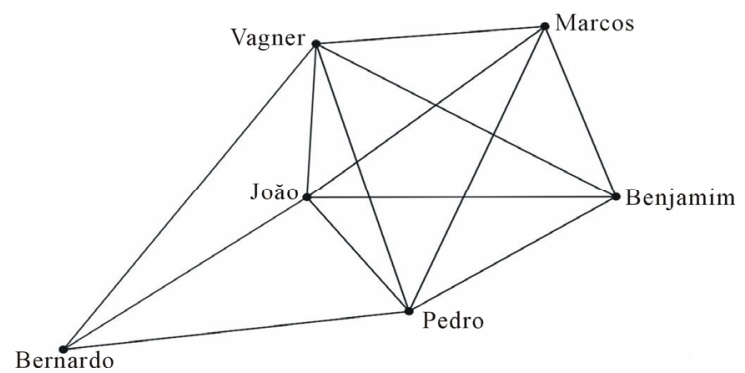

Figure 2. Subgroup of fish-farmers in the COOPISC learning network.

Table 4. Highest degree centrality among COOPISC members.

\begin{tabular}{lcc}
\hline & COOPISC member & Value \\
\hline 1 & Vagner & 48.718 \\
2 & Pedro & 47.436 \\
3 & Marcos & 33.333 \\
4 & Benjamin & 32.051 \\
5 & João & 31.410 \\
6 & Lucas & 16.026 \\
7 & Bernardo & 16.026 \\
\hline
\end{tabular}

Source: research data.

Table 5. Metrics for COOPISC subgroup.

\begin{tabular}{cc}
\hline Metric & Value \\
\hline Number of Individuals & 6 \\
Number of Ties & 23 \\
Density & 0.767 \\
Reciprocity & 0.769 \\
Clustering Coefficient & 0.803 \\
Betweenness Centrality & 0.165 \\
Closeness Centrality & 0.284 \\
\hline
\end{tabular}

Source: research data. 
with the subgroup density, it can be identified that the entire network ties are more scattered and less inteNES. We find that the subgroup, because of the high intensity of their internal relations, is more likely to generate learning, given that each subgroup member indicated other members as a source of learning through information and experience exchanges.

The reciprocity index is present in approximately $77 \%$ of relations, which indicates that mutual relations prevail in the subgroup. There are knowledge and learning exchanges by all members, thus ensuring the collective acquisition of knowledge from a range of individuals, as proposed by [20]. Thus, we can infer that inter-organizational learning exchanges will succeed in the subgroup rather than in the COOPISC network as a whole, which has a reciprocity index that is just only 0.302 . The high reciprocity in the subgroup demonstrates the ability of its pairs of members to maintain a relationship of mutual, not just individual, learning, which demonstrates the importance of reciprocity in combating opportunistic behavior.

The density and reciprocity indexes reflect the high value of the clustering coefficient. The percentage of $80.3 \%$ consists of the average probability that two nodes that have a common "friend" are directly connected. The high clustering coefficient is caused by the intensity and number of ties and also by the reduced number of members in the subgroup. Smaller groups tend to have a high clustering coefficient and are therefore more prone to becoming a source of inter-organizational learning. The proximity of members facilitates the experiences exchange and monitors the behavior of individuals, thereby increasing the confidence level.

The subgroup centrality indexes were a little higher compared to the entire network. The closeness centrality index is 0.284 , indicating that most relationships have a significant distance; however, it remains lower than the entire network (0.027). The implication of this higher index is that information can be more quickly transferred in the subgroup. The subgroup betweenness centrality index is 0.165 , whereas the entire network is 0.138 . This finding has no major implications because the fishfarmers with the highest degrees of betweenness in the COOPISC network as a whole are identical to the subgroup selected.

The subgroup composition and the level of cohesion between its members can be explained by the fact that all six fish-farmers are founders of COOPISC. All of them also have been living in the Mundo Novo municipality for over 20 years. Thus, the conditions for reputation, attitudes and past experiences of each fish-farmer with other members were generated over the years. Furthermore, primarily because they are part of the COOPISC foundation, these fish-farmers claimed that before the COOPISC establishment, they met frequently to discuss matters related to fish farming activities and strategic actions, as well as to exchange experiences. Perhaps this group of fish-farmers created strong ties based on trust over time, which can explain the high involvement in their inter-personal learning.

\section{Concluding Remarks}

The purpose of this paper was to identify the features of the social network formed by COOPISC fish-farmers through the structural analysis of networks and identification of critical actors. The analysis aims to provide data to encourage organizational knowledge sharing in the network and to identify the importance of the social network in obtaining inter-organizational learning. The results demonstrate that in the COOPISC knowledge sharing network, there are low levels of cohesion among members, which can hinder the efficiency of the interorganizational learning process.

The metrics of social network analysis revealed that within the COOPISC learning network stands a group of fish-farmers that constitute the core of knowledge transfer, whereas other members only establish peripheral relations with the core group. An analysis of the network formed by this subgroup of six fish-farmers was completed. The subgroup has relations with high degrees of cohesion and density, which demonstrates that their relationships are strong, closer and in greater number. The knowledge sharing in the COOPISC network occurs mainly by social contacts that extend beyond professional relationships to friendships, family relationships and common goals. The knowledge sharing began with the search for competitive advantage and the foundation of COOPISC based on joint work. The process was consolidated over time with informal cooperation relationships and trust.

The high degree of cohesion and intensity of learning relationships in the subgroup confirm the proposition of the NES that transactions are based on reliable social relations. The subgroup learning relationships network is grounded on trust acquired over time and through the sharing of information, experiences and activities in which the reputations of the members involved are apparent.

In agribusiness, sources of learning are often used to exchange experiences between producers, neighbors and partners. In this atmosphere, the social network can be a breeding ground for obtaining competitive advantages and for the creating and sharing of knowledge. However, for inter-organizational learning to occur, that is, to obtain collective learning not only at the individual level, it is essential that the transmission of knowledge occurs without risks and uncertainties. Therefore, relationships based on trust and cooperation are the basis for learning in social networks. 
Finally, we highlight some limiting factors of the study; for instance, the study only considered a specific group of actors in the supply chain, and it did not measure the influence of the technical advisory bodies or suppliers in the generation of learning. Another limitation is the number of fish-farmers interviewed, as it was not possible to access all COOPISC members. An analysis with all members could generate other results, such as identifying more than one subgroup of learning within the network.

We suggest that future studies be performed with other themes that characterize the subset of learning and attempt to identify other forms of learning in the agribusiness supply chains, thereby comparing different chains to verify their similarity to the forms of learning.

\section{REFERENCES}

[1] J. E. Fensterseifer, "Internationalization and Cooperation: Two Imperatives for the Company in the Third Millennium," Electronic Review of Administration, Vol. 15, No. 3, 2000, pp. 1-9.

[2] R. M. Teixeira and A. Morrison, "Development of Businessmen in Small Size Companies in the Hotel Industry: The Process of Learning, Skills and Social Networks," Journal of Contemporary Administration, Vol. 8, No. 1, 2004, pp. 105-128. doi:10.1590/S1415-65552004000100006

[3] J. H. Davis and R. A. Goldberg, "A Concept of Agribusiness,” Division of Research, Graduate School of Business Administration, Harvard University, Boston, 1957, 136p.

[4] E. Talamini and G. M. V. Ferreira, "Merging Netchain and Social Network: Introducing the 'Social Netchain' Concept as an Analytical Framework in the Agribusiness Sector,” African Journal of Business Management, Vol. 4, No. 3, 2010, pp. 2981-2993.

[5] R. M. Marteleto, "Analysis of Social Networks-Application in the Studies of Information Transfer," Information Science, Vol. 30, No. 1, 2001, pp. 71-81. doi:10.1590/S0100-19652001000100009

[6] A. F. D. Silva, "Analysis of Informal Social Networks and Organizational Knowledge Sharing," Master Dissertation, Centre of Humanities and Social Sciences, Federal University of Santa Maria, Santa Maria, 2010.

[7] M. S. Granovetter, “The Strength of Weak Ties,” American Journal of Sociology, Vol. 78, No. 6, 1973, pp. 13601380. doi:10.1086/225469

[8] C. H. J. Raud-Mattedi, "Critical Analysis of Mark Granovetter's Economic Sociology: The Limits of a Reading Market in Terms of Networks and Embeddedness," Politics \& Society, Vol. 4, No. 6, 2005, pp. 59-82.

[9] R. Marques, “The Rails of New Economic Sociology,” In: R. Marques and J. Peixoto, Eds., Nova Sociologia Econômica: Uma Antologia, Celta Editora, Oeiras, 2003, pp. 1-67.

[10] B. Uzzi, "Social Structure and Competition in Interfirm Networks: The Paradox of Embeddedness," Administra- tive Science Quarterly, Vol. 42, No. 1, 1997, pp. 35-67. doi:10.2307/2393808

[11] A. Balestrin and L. M. Vargas, "The Strategic Dimension of Horizontal Networks of SMEs: Evidences and Conceptualizations," Journal of Contemporary Administration, Vol. 8, 2004, pp. 203-228. doi:10.1590/S1415-65552004000500011

[12] J. B. Barney and M. H. HaNESn, "Trustworthiness as a Source of Competitive Advantage,” Strategic Management Journal, Vol. 15, No. s1, 1994, pp. 175-190. doi:10.1002/smj.4250150912

[13] S. P. Shapiro, "The Social Control of Impersonal Trust," American Journal of Sociology, Vol. 93, No. 3, 1987, pp. 623-658. doi:10.1086/228791

[14] A. Parkhe, "Building Trust in International Alliances," Journal of World Business, Vol. 33, No. 4, 1998, pp. 417437. doi:10.1016/S1090-9516(99)80072-8

[15] E. Tsang, "Organizational Learning and the Learning Organization: A Dichotomy between Descriptive and Prescriptive Research,” Human Relations, Vol. 50, No. 1, 1997, pp. 73-89. doi:10.1177/001872679705000104

[16] M. M. Crossan, H. W. Lane and R. E. White, “An Organizational Learning Framework: From Intuition to Institution," Academy of Management Review, Vol. 24, No. 3, 1999, pp. 522-537. doi:10.5465/AMR.1999.2202135

[17] J. Dyer and K. Nobeoka, “Creating and Managing a High-Performance Knowledge-Sharing Network: The Toyota Case," Strategic Management Journal, Vol. 21, No. 3, 2000, pp. 345-367.

doi:10.1002/(SICI)1097-0266(200003)21:3<345::AID-S MJ96>3.0.CO;2-N

[18] A. Dibella, "Developing Learning Organizations: A Matter of Perspective," Academy of Management Journal, Vol. 10, No. 3, 1996, pp. 287-290.

[19] I. Nonaka and H. Takeuchi, "Knowledge Creation in the Company,” 2nd Edition, Campus Elsevier, Rio de Janeiro, 1997.

[20] R. Larsson, L. Bengtsson, K. Henriksson and J. Sparks, "The Interorganizational Learning Dilemma: Collective Knowledge Development in Strategic Alliances,” Organization Science, Vol. 9, No. 3, 1998, pp. 285-305. doi:10.1287/orsc.9.3.285

[21] N. Levinson and M. Asahi, "Cross-National Alliances and Interorganizational Learning," Organizational Dynamics, Vol. 24, No. 2, 1995, pp. 50-64. doi:10.1016/0090-2616(95)90071-3

[22] S. Wasserman and K. Faust, "Social Network Analysis: Methods and Applications," Cambridge University Press, Cambridge, 1994. doi:10.1017/CBO9780511815478

[23] IBGE, “Cidades: Mundo Novo, MS,” 2012. http://www.ibge.gov.br/cidadesat/painel/painel.php?codm un $=500568$.

[24] A. C. Zen and D. Wegner, “The Knowledge Exchange in Interorganizational Networks: The Case of Gaucho Business Incubators and Technology Parks Network," Proceedings of the Seminars of Management, SEMEAd, São Paulo, 2008.

[25] J. Child, “Learning through Strategic Alliances,” In: M. 
Dierkes, et al., Eds., Organizational Learning and Knowledge, Oxford University Press, Oxford, 2001, pp. 657680.

[26] J. C. V. Reinhardt, "Computational Model to Team Formation Based in the Social Network of Team Leader," Master Dissertation, Graduate Program in Electric Engineering and Industrial Informatics, CPGEI, Federal University of Technology of Paraná, Curitiba, 2008.

[27] M. C. M. D. Silva, "Interorganizational Informal Social Networks and Management: A Study in the Areas of Maintenance and Plant Operation HYCO-8, CamaçariBA,” Master Dissertation, Management School, Graduate Program in Management, Federal University of Bahia, Salvador, 2003.

[28] J. Scott, "Social Network Analysis: A Handbook," 2nd Edition, Sage Publications, California, 2000.

[29] M. W. Lago Junior, "Interorganizational Informal Social Networks and the Organizational Processes and Changes: Study in a Company of Information Technology,” Master Dissertation, Management School, Graduate Program in Management, Federal University of Bahia, Salvador, 2005

[30] G. Radomsky and S. Schneider, "In the Webs of Economy: The Role of Social Networks and Reciprocity in Local Development Process,” Society and State, Vol. 22, No. 2, 2007, pp. 249-284. doi:10.1590/S0102-69922007000200003

[31] K. Ehrlich and I. Carboni, "Inside Social Network Analy- sis,” IBM Technical Report, 2005, pp. 5-10. http://ppr.cs.dal.ca/sraza/files/social\%20networks\%281\% 29.pdf

[32] K. Stephenson and M. Zelen, "Rethinking Centrality: Methods and Examples," Social Networks, Vol. 11, No. 1, 1989, pp. 1-37. doi:10.1016/0378-8733(89)90016-6

[33] D. D. S. Carstens, “Structure of Interorganizational Relationships and Strategies of Enterprises in Hiperfarma Network,” Master Dissertation, Graduate Program in Management, Social and Applied Science Department, Federal University of Paraná, Curitiba, 2005, p. 249.

[34] L. C. Freeman, "Centrality in Social Networks: Conceptual Clarification,” Social Networks, Vol. 1, No. 3, 1978, pp. 215-239. doi:10.1016/0378-8733(78)90021-7

[35] M. I. Tomaél and R. M. Marteleto, "Social Networks: Actors Positions and Information Flow," Electronic Journal of Librarianship and Information Science, Vol. 11, No. 1, 2006, pp. 75-91. doi:10.5007/1518-2924.2006v11nesp1p75

[36] R. A. Hanneman, "Introduction to Social Network Methods,” University of California, Riverside, 2001.

[37] T. B. Azevedo, "Social Network Analysis through SNA Software and Data Mining: A Case Study on Undergraduate Classes," Master Dissertation, Graduate Program in Management System, Fluminense Federal University, Niterói, 2011.

\section{List of Abbreviations}

NES = New Economic Sociology; IBGE = Brazilian Institute of Geography and Statistics (in Portuguese); COOPISC $=$ Fish-Farmers' Cooperative of Mundo Novo. 